\title{
AVALIAÇÃO DO IMPACTO DO PROGRAMA DE REFORMA AGRÁRIA FEDERAL NO CEARÁ: UM ESTUDO DE CASO
}

\author{
Germano Silva Maia* \\ Ahmad Saeed Khan ${ }^{+}$ \\ Eliane Pinheiro de Sousa $\ddagger$
}

\begin{abstract}
Resumo
Este estudo objetiva avaliar o impacto do programa federal de assentamento agrícola no estado do Ceará sobre a sustentabilidade de seus beneficiários. Para isso, construíram-se índices com dados não pareados e aplicou-se um método de pareamento baseado no escore de propensão (Propensity Score Matching), utilizando dados primários coletados junto aos produtores rurais beneficiários e não beneficiários. Os resultados da análise sem pareamento mostraram-se bastante semelhantes aos obtidos com pareamento, que apontam a não efetividade dessa política pública na geração de impactos significativos na qualidade de vida, desenvolvimento ambiental e político institucional para seus beneficiários comparativamente aos não contemplados pela política.
\end{abstract}

Palavras-chave: Programa de Reforma Agrária; Sustentabilidade; Propensity Score Matching.

\begin{abstract}
This study aims to assess the impact of the federal agricultural settlement program on the sustainability of its beneficiaries in the state of Ceará. In order to achieve such goal, unpaired data indices were built and a pairing method based on the propension score (Propension Score Matching) was applied, by using primary data collected alongside beneficiary and non-beneficiary farmers. The results of the unpaired analysis showed to be very similar to those obtained with the pairing analysis, which indicate the non-effectiveness of this public policy on the generation of significant impacts on the quality of life, on environmental and politicalinstitutional development for their beneficiaries, when compared to those not encompassed by such policy.
\end{abstract}

Keywords: Land Reform Program; Sustainability; Propensity Score Matching.

JEL classification: C14, Q18

\footnotetext{
* Universidade Federal do Ceará. Departamento de Economia Agrícola. E-mail: germanomaia@hotmail.com

† Universidade Federal do Ceará. Departamento de Economia Agrícola. E-mail: saeed@ufc.br

‡ Universidade Regional do Cariri. Departamento de Economia. E-mail: pinheiroeliane@hotmail.com
} 


\section{Introdução}

A reforma agrária é um dos mais polêmicos, controversos e complicados temas a serem analisados, avaliados e superados pelo Brasil com opiniões distintas e plurais. A esse respeito, Buainain (2008, p. 10) destacam:

"Como em vários outros assuntos debatidos no Brasil, adicionese à multideterminação das causas dos conflitos as diferenças de visão de mundo. Estas, muitas vezes, refletem posições necessariamente excludentes: para uns, os conflitos revelam e indicam a emancipação e conquista de cidadania dos pobres, que vão à luta por seus direitos; para outros, a insuficiência institucional - que não logra nem protege os direitos de propriedade e nem assegura os direitos básicos dos que terminam sendo obrigados a aderir ao conflito".

Segundo Heredita et al. (2002) e Medeiros e Deere (2005) apud Leite \& Ávila (2007), a reforma agrária gerou efeitos positivos na esfera municipal brasileira, como a diversificação da produção agrícola, a ampliação do mercado d trabalho e o fortalecimento político dos beneficiários, cujas demandas por infraestrutura fsica e social não podem ser desconsideradas. Além disso, as famílias passam ter acesso a outros tipos de benefícios quando recebem uma arcela de terra, co m créditos para a construção de casas e plantio, geran o efeitos multiplicador es sbre o restante da economia.

Na concepção de Sachs (2008), a reforma agrária, quando bem conduzida, que cobre resultados produtivos dos seus beneficiários e incentive a lógica empreende ora dos assentados, pode ampliar o setor da agricultura familiar viável, ge ando empregos a um custo inferior a qualquer alternativa urbana.

Mesmo levando-se em conta a significativa heterogeneidade dos assentamentos encontrados no país assim como as precárias infraestruturas, conforme Leite \& Ávila (2007), quando se compara a situação pretérita e presente dos assentados constatam-se melhorias em suas condições de vida, sendo que tais benefícios são potencializados quando ocorre a concentração de projetos, contribuindo para uma maior reformulação da realidade regional.

De acordo com as constatações do estudo de Alves (2011), com base no Censo Agropecuário de 1995-1996, relativo ao Nordeste, pode-se verificar que $64 \%$ dos estabelecimentos pertenciam à categoria de proprietários. Já no Censo de 2006, verificou-se que esse valor cresceu para $69 \%$ dos produtores. Comparando os dois censos, pode-se ainda perceber que o número de estabelecimentos e a área ocupada por produtores com acesso temporário ou de forma precária a terra, ainda é bastante elevado. Pode-se extrair, também, que os Estados nordestinos com as maiores concentrações de Produtores Sem Área ${ }^{1}$ são o Maranhão $(20,5 \%)$ e o Ceará $(10,4 \%)$.

Embora exista mercado para a produção familiar, que é o tipo de produção realizada em assentamentos e projetos de colonização, não é possível justificar os custos das políticas que visam ao seu fomento somente com base nesse fato.

\footnotetext{
${ }^{1}$ Com base no Censo Agropecuário de 2006, quando identificada uma atividade de produção ou criação em um estabelecimento agrícola, com a presença de produtores empregados, porém, sem que nesta ocorresse a participação de um produtor proprietário, classificou-se esse produtor empregado como Produtor Sem Ârea.
} 
Outro argumento mais relevante consiste na grande necessidade de se manter o vasto excedente de mão de obra do meio rural no campo. Isso porque a migração em massa e continuada de trabalhadores para os médios e grandes centros urbanos gera o agravamento de problemas vividos nas zonas urbanas. Além de conter o êxodo rural, os programas de assentamento possuem, também, um caráter mitigador de pobreza e redutor de desigualdades sociais.

No Ceará, existe o programa de reforma agrária executado pelo Instituto Nacional de Colonização e Reforma Agrária (INCRA). As cifras investidas por esse programa nas aquisições das terras e nas verbas complementares conduzem a uma expectativa de que, ao visitar um assentamento, o investigador se deparará com pequenos núcleos dinâmicos e em acelerado processo de desenvolvimento. Ao contrário, ao se ter acesso a um assentamento agrícola — após se constatar a grande dificuldade de acesso à maioria deles - o cenário faz surgir questionamentos nas mais diversas perspectivas.

Os estudos contidos na literatura econômica têm centrado no diagnóstico dos programas de reforma agrária, porém não têm focado na mensuração de impacto, constituindo uma contribuição deste estudo em relação às pesquisas realizadas. Em termos de impacto da reforma agrária, encontrou-se o estudo da FAO (1995) apud Leite (2011), que selecionou uma amostra de 44 assentamentos fundados entre 1985 e 1989 dispersos por todo o país para verificar o impacto dessa política sobre a qualidade de vida das populações assentadas.

Tendo em vista que este estudo citado incorporou apenas a qualidade de vida, reveste-se de importância a realização do presente trabalho, que busca avaliar o impacto do programa de reforma agrária federal no estado do Ceará sobre a sustentabilidade de seus beneficiários, contemplando as dimensões concernentes à qualidade de vida, capital social, político institucional e desenvolvimento ambiental. Além disso, este estudo também inova quanto ao método utilizado para atender aos objetivos propostos, já que se emprega Propensity Score Matching. Essa ferramenta analítica tem sido largamente empregada para avaliar o impacto de políticas públicas, como, por exemplo, PRONAF (Programa Nacional de Fortalecimento da Agricultura Familiar), elaborado por Magalhães et al. (2006), Bolsa Escola, desenvolvido por Resende \& Oliveira (2008), e Bolsa Família, realizado por Duarte et al. (2009), porém não se encontraram estudos que adotassem esse método para avaliar o impacto da reforma agrária.

Além desta seção introdutória, o estudo também é constituído por quatro seções, sendo que, na segunda, descrevem-se os fundamentos teóricos relativos à reforma agrária e desenvolvimento sustentável. A área de estudo, a natureza dos dados, o tamanho da amostra e os métodos analíticos são apresentados na terceira seção. Em seguida, são mostrados e discutidos os resultados, e a última seção é destinada às conclusões e sugestões.

\section{Referencial Teórico}

\subsection{Reforma Agrária}

A Constituição da República Federativa do Brasil, de 1988, define a reforma agrária como uma releitura ou novo conjunto de leis com a finalidade de disciplinar a estrutura agrária do país. Ela deve atender aos objetivos de valorização do trabalhador rural e aumento da produção. Dentre outras, ela estabelece como uma de suas principais metas o combate aos minifúndios e latifúndios, 
bem como toda e qualquer outra forma menos adequada de produção. Como se pode apreender do texto constitucional, a grande função da reforma agrária é reforçar a função social da terra e contribuir para o aumento da produção agrícola. Ela é progressista no sentido de assegurar uma base jurídica para atualizações nas normas que regem a estrutura fundiária, em cada novo contexto histórico. Ao mesmo tempo, ela é conservadora, uma vez que descreve uma série de mecanismos para a promoção da reforma sem, no entanto, deixar de priorizar o direito à propriedade privada.

Com base em Pedro (2008), existem duas definições para Reforma Agrária. A primeira foi realizada pelas burguesias industriais no final do século XIX e durou até pouco depois da Segunda Guerra Mundial. Ela apresenta três características principais: atingiu todas as grandes propriedades do país, em algumas nações impôs tamanho máximo às propriedades e foi realizada em pouco tempo, um ou dois anos. A segunda definição revela uma confusão entre o conceito de reforma agrária e o de política de assentamentos. Segundo o autor, o simples ato de assentar famílias pode não afetar a atual estrutura fundiária de uma nação, caso não seja massivo e rápido. Essas duas definições descritas caracterizam a forma como se promoveu a reforma agrária em muitos dos países desenvolvidos e como vem se dando esse processo em boa parte dos países periféricos, notadamente, identificado-o com o caso brasileiro, no já caracterizado processo de reforma conservadora.

Com base nos dados do INCRA (2009), do período de 1995 a 2002, o governo avançou significativamente na questão da reforma agrária. Somente nos quatro primeiros anos desse governo (1995-1998), foram assentadas 287.994 famílias, ao passo que em toda a história anterior a esse governo haviam sido assentadas 218.033 famílias (excluindo-se os projetos de colonização), ou seja, quase 70 mil famílias a mais que em toda a história do país. Esse período foi marcado pela implementação de projetos que convergiram para esse fim, como: Programa de Crédito Especial para a Reforma Agrária (Procera), criado em 1985, mas operacionalizado com vigor a partir de 1995; Projeto Lumiar, de 1997; Projeto Emancipar, de 1997; Programa do Banco Interamericano de Desenvolvimento (BID); Programa Cédula da Terra, de 1997, como também pela maciça desapropriação de terras improdutivas e griladas.

O governo dos anos de 2003 a 2010, já em seu princípio, deparou-se com uma nova exigência na área da reforma agrária. O Governo anterior fora um sucesso em termos quantitativos, porém, no tocante à qualidade e promoção de investimentos complementares que viabilizassem a sustentabilidade dos projetos, ficou a desejar. Essas exigências qualitativas foram as primeiras sofridas por esse governo. Sem grandes inovações, continuou grande parte dos programas desenvolvidos pelo governo anterior.

No programa de reforma agrária executado por intermédio do Instituto Nacional de Colonização e Reforma Agrária (INCRA) no estado do Ceará, os recursos utilizados na aquisição das terras não são reembolsados, ou seja, a terra é doada e os recursos aportados são $100 \%$ a fundo perdido. Segundo Hartmann (2000), para fins de reforma agrária, o INCRA pode desapropriar terras improdutivas e reparti-las entre minifundiários e trabalhadores rurais, que são assentados em conjuntos de diversas famílias. Além disso, o INCRA se compromete a fornecer infraestrutura, assistência técnica e instituições de educação e saúde, porém essas medidas ficam a desejar, pois são realizadas de forma muito lenta. 


\subsection{Desenvolvimento Sustentável}

Historicamente, conforme Barreto (2004), esse conceito teve origem em uma entidade denominada "Clube de Roma", que era constituída por grupos de intelectuais e empresários que, ao contrário do que possa parecer, não foi formada com o intuito de militar sobre as questões ecológicas. Essa entidade foi responsável pela produção dos primeiros estudos científicos sobre a preservação do meio ambiente, cujos resultados iniciais foram publicados entre 1972 e 1974. Com o intuito de se atingir a sustentabilidade, resultados indicaram a necessidade de solucionar quatro questões: o controle do crescimento da população, o controle do crescimento da industrialização, a insuficiente produção de alimentos e o colapso dos recursos naturais.

O crescimento das discussões sobre esse tema, ao mesmo tempo em que cresciam os movimentos ambientalistas, levou essa questão ao nível de problema mundial. Esse foi consagrado em Estocolmo, na Suécia, em 1972, quando foi realizada a Primeira Conferência das Nações Unidas sobre o Meio Ambiente. Como resultado imediato dessa conferência, teve-se a elaboração de 27 princípios norteadores da relação homem-natureza, que se tornariam, mais tarde, a base teórica para a formulação do conceito de Desenvolvimento Sustentável.

A primeira definição oficial para o conceito de Desenvolvimento Sustentável foi produzida em 1987, fazendo parte de um documento denominado "Nosso Futuro Comum", elaborado pela Comissão Mundial para o Meio Ambiente e Desenvolvimento, presidida pela primeira ministra da Noruega Sra. Gro Harlem Brundtland. Esse documento ficou conhecido como "Relatório de Brundtland", o qual continha, além da definição oficial, um conjunto de métodos e recomendações a serem seguidas pelas nações participantes da comissão, para enfrentar a crise que o mundo passava. Em linhas gerais, o texto desse documento versava sobre a impossibilidade de se atingir o desenvolvimento sem uma significativa redução das desigualdades sociais e condenava, de maneira enfática, os atuais modelos de crescimento econômico que não se ocupavam de verificar sua sustentabilidade no longo prazo (Barreto 2004).

De forma complementar, segundo o Relatório de Brundtland, citado pela Comissão Mundial sobre Meio Ambiente e Desenvolvimento CMMAD (1991), o Desenvolvimento Sustentável pode ser conceituado como:

[...] aquele que satisfaz as necessidades do presente sem comprometer a capacidade das gerações futuras de satisfazerem as suas próprias necessidades", "um processo de mudança no qual a exploração dos recursos, a orientação dos investimentos, os rumos do desenvolvimento tecnológico e a mudança institucional estão de acordo com as necessidades atuais e futuras [...].

Se por um lado o relatório logrou um satisfatório resultado com a formulação de uma definição oficial para o conceito de desenvolvimento sustentável, por outro, deixou a desejar no tocante à listagem de quais seriam essas necessidades a serem satisfeitas, como seriam atendidas e a que grupo de indivíduos tais conjuntos de necessidades pertencem.

Toda essa perspectiva de ações práticas, que buscam atender aos objetivos traçados no conceito oficial, só foi formalizada em um plano de ação estratégica para o Desenvolvimento Sustentável global denominado de "Agenda 21". Esse foi um dos documentos resultantes da Conferência das Nações Unidas 
para o Meio Ambiente, realizada na cidade do Rio de Janeiro em 1992. Esse documento foi assinado por 174 chefes de governos. A "Agenda 21" tinha entre suas metas identificar parceiros e metodologias para a obtenção de consensos e meios de colocá-los em prática e acompanhá-los. Em seu capítulo 40, o que tratava do plano de ação, havia 200 propostas de mudanças para serem efetivadas a partir daquela data. Essas propostas foram reforçadas nos resultados da $3 \nmid$ Conferência sobre Desenvolvimento Sustentável, a RIO+10, realizada em Johanesburgo - África do Sul, em 2002.

Um dos principais resultados dessa última conferência foi um verdadeiro clamor pela elaboração de indicadores de desenvolvimento sustentável. Essa urgência deve-se ao fato de que somente após a concepção destes é que se poderiam realizar avaliações do desempenho das nações no tempo. Além disso, esses indicadores poderiam subsidiar a concepção de políticas públicas e privadas que visassem o desenvolvimento sustentável.

De acordo com Sachs $(2002,2008)$, o conceito de desenvolvimento sustentável apresenta cinco dimensões: social, ambiental, territorial, econômica e política. A dimensão social considera a busca pela redução da desigualdade social, distribuição de renda justa, emprego que assegure a qualidade de vida e acessibilidade aos recursos e serviços sociais. A dimensão ambiental abrange os sistemas de sustentação da vida como provedores de recursos e como "recipientes" para a disposição de resíduos. A dimensão territorial está relacionada à distribuição espacial dos recursos, das populações e das atividades. A dimensão econômica contempla a alocação e distribuição eficientes dos recursos naturais, representando uma condição fundamental para que as coisas aconteçam. Por fim, a dimensão política busca a governança democrática, que constitui um componente básico da sustentabilidade. Dentre essas dimensões, apenas a dimensão territorial não foi incorporada neste estudo.

Para Abramovay (2010), o desenvolvimento sustentável é constituído por um complexo de fatores basilares. Por sua vez, estes necessitam, fundamentalmente, de um compromisso estratégico de todos os atores sociais, sob pena de romper com seu andamento. Segundo esse autor, o que está posto à prova é a capacidade das sociedades humanas de cooperar e decidir como ocorrerá o uso dos recursos naturais dos quais tanto dependem.

\section{Metodologia}

\section{1 Área de estudo, natureza dos dados e tamanho da amostra}

A área de interesse para o estudo foi a microrregião do Baixo Jaguaribe, no estado do Ceará. Sua escolha pode ser atribuída à razoável homogeneidade e à existência de um bom número de municípios contendo assentamento do Programa. Segundo a classificação do Instituto de Pesquisa e Estratégia Econômica do Estado do Ceará IPECE (2011), essa região é composta por dez municípios, sendo que este estudo contemplará os municípios de Russas, Tabuleiro do Norte, Morada Nova e Ibicuitinga, em virtude desses municípios possuírem assentamentos do INCRA.

No tocante à natureza dos dados, este estudo utilizou dados primários oriundos da aplicação de questionários semiestruturados aos agricultores beneficiários do programa de reforma agrária executado pelo INCRA e aos agricultores familiares não proprietários e não assentados. Além disso, empregaramse dados secundários obtidos do Instituto de Pesquisa e Estratégia Econômica 
do Ceará (IPECE), Instituto Brasileiro de Geografia e Estatística (IBGE), e Ministério do Desenvolvimento Agrário (MDA), como também dados provenientes de livros, teses, dissertações e revistas.

A amostra do presente estudo foi selecionada de forma não aleatória, seguindo os trabalhos desenvolvidos por Magalhães et al. (2006), Resende \& Oliveira (2008) e Duarte et al. (2009), que empregaram o método analítico de Propensity Score Matching.

De acordo com Duarte et al. (2009), a aplicação desse método admite que sejam atendidas as pressuposições do balanceamento das características observáveis, isto é, a seleção da amostra exige que a participação no programa em análise independa dos resultados e seja condicional nas covariáveis; e da presença de um suporte comum para que não se compare o incomparável, o que ocasionaria viés na avaliação. Assim, para cada grupo de controle, há um de tratamento correspondente.

Portanto, buscou-se selecionar entrevistados beneficiários e não beneficiários em condições quase similares em todos os aspectos tratados nesse estudo, inclusive quanto à localização. O tamanho da amostra dos beneficiários (50 assentados) representa $10 \%$ do total de agricultores beneficiados pelo programa, enquanto a amostra do grupo de controle foi igual ao tamanho do grupo de tratamento acrescida de $40 \%$. Portanto, entrevistaram-se 50 famílias beneficiárias do programa do INCRA e 70 famílias de produtores não beneficiários.

\subsection{Métodos analíticos}

Para atender aos objetivos propostos, foram construídos índices com dados não pareados, sendo que, com o intuito de avaliar melhor tais índices, empregaramse testes estatísticos paramétricos, e aplicou-se um método de pareamento baseado no escore de propensão (Propensity Score Matching).

\section{Índice de Sustentabilidade}

O Índice de Sustentabilidade (IS) foi utilizado com o intuito de mensurar a sustentabilidade da realidade vivenciada pelas famílias de não beneficiários e beneficiários do programa de reforma agrária.

Com base no estudo de Damasceno et al. (2011), para calcular o índice de sustentabilidade, foram incluídos quatro índices: Qualidade de Vida, Capital Social, Político Institucional e Desenvolvimento Ambiental, podendo ser expresso por:

$$
I S=\frac{1}{F} \sum_{L=1}^{F} I L
$$

em que: $I S=$ Índice de Sustentabilidade; $I L=$ Escore do $l-$ simo índice $I ; L=$ $1, \ldots, F$ (índices).

A partir dessa expressão, percebe-se que este índice é formado pela média aritmética dos escores dos demais índices. Ele situa-se no intervalo entre $0 \leq I S \leq 1$, sendo que quanto mais próximo de zero, menor é a sustentabilidade e quanto mais próximo de um, maior a sustentabilidade. O nível de sustentabilidade é considerado baixo quando estiver no intervalo entre $0 \leq I S \leq 0,5$; médio se estiver entre $0,5<I S \leq 0$, 8 ; e alto quando fizer parte do intervalo entre $0,8<I S \leq 1$. 
Como se empregou o mesmo procedimento metodológico para definir esses índices, conforme Damasceno et al. (2011), matematicamente, tais índices podem ser representados de forma genérica por:

$$
I(L)=\frac{1}{S} \sum_{k=1}^{S} C_{k}
$$

em que: $L=$ Qualidade de Vida; Desenvolvimento Ambiental; Capital Social; e Político Institucional.

Para se obter a contribuição individual de cada indicador que compõe o índice, usa-se:

$$
C_{k}=\frac{1}{M} \sum_{j=1}^{m}\left[\frac{1}{n} \sum_{i=1}^{n}\left(\frac{E_{i j}}{E_{\max i}}\right)\right]
$$

em que: $I L=$ Índice $\mathrm{L} ; C_{k}=$ Contribuição do indicador " $k$ " no índice $\mathrm{L}$; $E_{i j}=$ Escore da $i$-sima variável do indicador " $k$ " obtido do $j-$ simo produtor; $E_{\max i}=$ Escore máximo da $i-\operatorname{sima}$ variável do indicador " $k$ "; $i=1, \ldots, n$ (variáveis que compõem o indicador " $k$ "); $j=1, \ldots, m$ (produtores); $k=1, \ldots, s$ (indicadores que compõem o índice $L$ ).

Seguindo Damasceno et al. (2011), o índice $L$ apresentou a seguinte parametrização: de $0 \leq I(L) \leq 0$, 5; tem-se um baixo nível de $L$; de $0,5<I(L) \leq 0$, 8 ; tem-se um médio nível de $L$; e de $0,8<I(L) \leq 1$; tem-se um alto nível de $L$.

Cada índice é formado por um conjunto de indicadores. Na composição do Índice de Qualidade de Vida (IQV), foram consideradas as dimensões referentes à saúde; habitação; saneamento e higiene; e bens duráveis.

No tocante à dimensão saúde, foram considerados os indicadores que concernem a acesso a serviços de saúde e ao acesso a medicamentos para o tratamento. Quanto à dimensão habitação, levaram-se em consideração os seguintes indicadores: forma de cessão de uso da residência; tipo de construção do domicílio; e energia utilizada na residência. No que tange à dimensão do saneamento e higiene, foram considerados os indicadores a seguir: acesso à água; tratamento da água para consumo humano; destino dado ao lixo do domicílio; e tipo de escoadouro do banheiro ou sanitário. Em relação à dimensão dos bens duráveis, foi considerado o acesso aos seguintes bens duráveis: geladeira, moto ou carro, televisão, fogão a gás, antena parabólica, som, e liquidificador.

$\mathrm{Na}$ formação do Índice de Desenvolvimento Ambiental (IDA), consideramse os indicadores que identificam a prática de conservação utilizada; o método de controle de pragas adotado na unidade produtiva; os tipos de agrotóxicos utilizados; se utilizou queimadas em suas atividades agropecuárias; o destino dado aos restos da produção; se foi feito plantio de árvores objetivando a conservação do solo; se existia alguma área de reserva de mata nativa na propriedade; se a residência possuía algum sistema de esgoto ou tipo de fossa; se foi feita a rotação de terras; se fez calagem, caso fosse necessário; se foi feita a análise do solo; se fez adubação verde; se utilizou material orgânico; e se fez uso do solo de acordo com a sua vocação.

O Índice de Capital Social (ICS) contempla os indicadores em que se questionou se as pessoas sempre se preocupam mais com o bem-estar próprio e de seus familiares do que com o bem-estar da comunidade; o grau de influência que acreditam ter para tornar a comunidade um lugar melhor para viver; se são convidadas a participar das reuniões/assembleias da associação; 
se frequentam as reuniões da associação; se todas as questões levantadas nas reuniões são respondidas; se participam da escolha dos líderes da associação; se as decisões são aprovadas em reuniões/assembleias; se apresentam sugestões nas reuniões; se as decisões tomadas são realmente postas em prática ou adotadas; se os líderes da associação prestam contas aos associados; se contribuiem com cotas ou taxas; se participam de eventos organizados pela associação; caso tenham um problema, se sempre aparecerá alguém da comunidade para ajudar; se estão satisfeitas com o processo de escolha de seus dirigentes; se confiam na maioria dos membros da comunidade ou sócios da associação; se confiam nos líderes da comunidade ou na maioria da diretoria da associação; e se acreditam em sua capacidade de contribuir para solucionar os problemas da sua comunidade.

O Índice Político Institucional (IPI) é composto por indicadores, em que se buscou saber se receberam assistência técnica pública; se receberam crédito de instituição pública; se receberam algum produto ou serviço da Secretaria de Agricultura Municipal ou Estadual; e se participaram de algum programa ou curso de capacitação do poder público.

A escolha desses indicadores foi baseada nos estudos sobre sustentabilidade em assentamentos de reforma agrária realizados por Guerra (2002), Barreto et al. (2005), Sousa et al. (2005) e Alves \& Bastos (2011).

\section{Testes Estatísticos}

Conforme descrito, com intuito de melhor avaliar os resultados dos índices, foram utilizados testes estatísticos paramétricos de Levene para verificar a homogeneidade ou não das variâncias dos grupos comparados e teste $t$ de Student para comparação de duas médias de dados não pareados, ${ }^{2}$ calculados com auxílio do programa SPSS, versão 17.0.

Levene (1960) desenvolveu uma estatística para testar a homogeneidade de variâncias em dados balanceados ${ }^{3}$ e que, mais tarde, foi generalizada para dados não balanceados. A estatística utilizada no teste é obtida a partir de uma análise de variância baseada em um único fator. Isso porque o nível de observação é a população, então ocorre a substituição de cada item $i$ pelo desvio absoluto da variável em relação à média do seu respectivo grupo.

Supondo que se tome $K \leq 2$ amostras aleatórias e independentes, sendo que cada amostra $i$ corresponde a um conjunto de $n_{i}$ variáveis aleatórias, as quais foram comparadas para testar a hipótese nula de igualdade entre as variâncias, representada por (4) e a hipótese alternativa de que nem todas as variâncias são iguais, indicada por (5).

$$
\begin{gathered}
H_{0}=\sigma_{1}^{2}=\ldots=\sigma_{k}^{2}, i=1, \ldots, k \\
H_{1}=\sigma_{i}^{2} \neq \sigma_{j}^{2}, \text { para algum } i \neq j, j=1 \ldots, k
\end{gathered}
$$

Em seguida, a equação (6) descreve o valor de $Z$ - desvios absolutos de $X$ com relação às médias amostrais dos grupos:

\footnotetext{
${ }^{2}$ Dados pareados são dados resultantes do desempenho antes e depois de um tratamento, ou seja, remete-se à mesma amostra em tempos diferentes, enquanto os dados não pareados são aqueles resultantes de comparações de dois tratamentos quaisquer, que correspondem a amostras diferentes em um dado momento.

${ }^{3}$ Dados balanceados são aqueles que possuem o mesmo tamanho de amostras, enquanto os dados não balanceados são aqueles que possuem amostras de tamanho diferente.
} 


$$
z_{i j}=\left|X_{i j}-\bar{X}_{i}\right|, j=1, \ldots, n_{i} \text { e } i=1, \ldots, k
$$

Em que:

$$
\bar{X}_{i}=n_{i}^{-1} \sum_{j=1}^{n_{i}} X_{i j}
$$

representa a média das amostras.

A estatística do teste de Levene pode ser definida por:

$$
w_{0}=\left(\frac{n-k}{k-1}\right) \frac{\sum_{i=1}^{k} n_{i}\left(\bar{Z}_{i .}-\bar{Z}_{. .}\right)}{\sum_{i=1}^{k} \sum_{j=1}^{n_{i}} n_{i}\left(\bar{Z}_{i j}-\bar{Z}_{i .}\right)^{2}}
$$

Em que: $\bar{Z}_{i .}=n_{i}^{-1} \sum_{j=1}^{n_{i}} Z_{i j}$

$$
\begin{gathered}
\bar{Z}_{. .}=n^{-1} \sum_{i=1}^{k} n_{i} \bar{Z}_{i .} \\
n=\sum_{i=1}^{k} n_{i}
\end{gathered}
$$

Por fim, o teste emprega a seguinte regra de rejeição.

Rejeita-se: $H_{0}$ se $w_{0}>F_{(k-1, n-l),(1-\alpha)}$

O segundo teste considerado neste estudo foi o teste $t$ de Student para dados não pareados. De acordo com Triola (1999), corresponde a um teste paramétrico, que permite comparar uma mesma variável, de duas amostras diferentes, em um dado instante no tempo. Esse teste apresenta duas suposições, a saber: as duas amostras precisam ser independentes e as amostras devem ser obtidas de forma aleatória e devem ser normalmente distribuídas.

Ressalta-se que se admitiu o Teorema Central do Limite. Segundo Triola (1999), esse teorema estabelece que em amostras de tamanho "suficientemente grande", as médias amostrais apresentam uma distribuição satisfatoriamente próxima da distribuição normal.

As hipóteses desse teste são:

Hipótese nula $\left(H_{0}\right): \mu_{1}=\mu_{2}$, não existem diferenças significativas entre as médias.

Hipótese alternativa $\left(H_{1}\right): \mu_{1} \neq \mu_{2}$, existem diferenças significativas entre as médias.

\section{Propensity Score Matching}

Para avaliar o impacto do programa de assentamento agrícola no estado do Ceará sobre a sustentabilidade de seus beneficiários, utilizou-se o modelo Propensity Score Matching. Segundo Duarte et al. (2009, p 907):

"Os estudos existentes, relacionados aos impactos de políticas públicas sobre variáveis de interesse, apontam como principal dificuldade a falta de informações a respeito dos indivíduos em situações diferentes, ou seja, dos indivíduos beneficiados e não beneficiados pela política". 
Esse modelo busca obter informações que sejam estatisticamente significativas, relativas a um conjunto de características ou variáveis de interesse, as quais permitam verificar a efetividade de uma política pública. No caso do presente estudo, o modelo busca selecionar, dentre um conjunto de características observadas na pesquisa de campo, quais são capazes de efetivamente diferenciar beneficiários e não beneficiários dos programas de assentamento agrícola em termos de características pré-existentes, ou seja, as que foram previamente determinadas.

O modelo é executado em duas etapas. Na primeira, estima-se um modelo Logit, que objetiva calcular a probabilidade de cada entrevistado ser beneficiado (escore de propensão) pelo programa de assentamento. Após $n$ combinações das variáveis observadas, para se obter o Logit com os melhores resultados, consideraram-se as seguintes variáveis: anos de estudo; idade; total de indivíduos na residência; renda não agrícola; bens duráveis; se é convidado a participar das reuniões (Dummy); se existe solidariedade entre os membros da comunidade (Dummy); se participa das eleições dos líderes da associação (Dummy); assistência técnica (Dummy), e se participou de curso de capacitação (Dummy). A seleção dessas variáveis preditoras que influenciam a probabilidade de participação no programa tomou como base os estudos desenvolvidos por Magalhães et al. (2006), Resende \& Oliveira (2008) e Duarte et al. (2009), que buscaram avaliar o impacto de políticas públicas. Além disso, é relevante ressaltar que a escolha dessa combinação de variáveis que resultaram na obtenção do modelo Logit com os melhores resultados, pode ser atribuída aos efeitos significativos dessas variáveis e à qualidade de ajuste do modelo.

A segunda etapa do modelo consiste na formação dos pares de beneficiários e não beneficiários, que possuem escore de propensão o mais semelhante possível, o que possibilita a análise dos impactos dos programas. Este estudo adotou como método de pareamento o método do vizinho mais próximo ( $\mathrm{Ne}$ arest Neighbour Matching). Assim:

$$
V\left((i)=\min _{j}\left\|p_{i}-p_{j}\right\|, i \in B\right.
$$

Em que: $V(i)=$ conjunto de observações do grupo de controle a serem relacionadas com o indivíduo $i$ do grupo de tratamento; $p_{i}$ e $p_{j}=$ significam as probabilidades de fazer parte do programa; e $B=$ grupo dos beneficiários.

Os valores dos ATTs (Average Effect of Treatment on Treated) são calculados a partir da diferença entre os valores médios que resultam do pareamento. Os ATTs apresentam-se com sinais negativos ou positivos, indicando o provável impacto do programa na variável resultado analisada. Neste estudo, as variáveis resultado são os índices calculados na primeira etapa do estudo, no entanto, essa primeira análise trata-se de uma análise não pareada.

Para validar as estimativas dos ATTs, foi adotado o procedimento de estatística inferencial denominado bootstrapping. Esse método baseia-se em uma amostragem repetida com reposição ou replicação, que permite a obtenção de erro padrão do estimador (no caso o ATT) e a verificação dos impactos significativos do programa avaliado. Neste estudo, para cada estimativa de ATT, foram realizadas 50 replicações.

A aplicação do método Propensity Score Matching foi realizada por meio do programa STATA versão 9, comandos psmatch2. 


\section{Resultados e Discussão}

\section{1 Índice de Sustentabilidade (IS) dos dados não pareados}

Os dados da Tabela 1 constatam que beneficiários do programa de reforma agrária, executado por intermédio do INCRA, obtiveram Índice de Sustentabilidade de 0,5853, o que permite classificar que, em média, esses beneficiários possuem médio nível de sustentabilidade. $\mathrm{O}$ indicador que menos contribuiu para o aumento do valor do índice foi o Índice de Desenvolvimento Ambiental.

Verifica-se também que os não beneficiários obtiveram Índice de Desenvolvimento Sustentável de 0,5004, o que os classifica como médio nível de sustentabilidade. Neste caso, o Índice de Capital Social foi o que mais contribuiu para reduzir o valor do índice.

Constata-se que os beneficiários do programa federal de reforma agrária obtiveram Índice de Qualidade de Vida (IQV) de 0,625, o que permite afirmar que, em média, seus beneficiários possuem médio nível de qualidade de vida, sendo que o indicador que menos contribuiu para este índice dos beneficiários foi o destino do lixo. Em contrapartida, o IQV dos não beneficiários foi de 0,689 , sendo que o indicador que menos contribuiu para a formação desse índice foi Escoadouro de Banheiro.

No tocante ao Índice de Desenvolvimento Ambiental (IDA), os dados da Tabela 1 apontam que os beneficiários e não beneficiários do programa de assentamento agrícola do INCRA obtiveram IDA de 0,411 e 0,408, respectivamente, o que sinaliza que, em média, ambos os grupos apresentam baixo nível de desenvolvimento ambiental. Os indicadores que menos contribuíram para o valor desse índice foram: tipo de prática de conservação utilizada; planta árvores para conservação do solo; faz análise do solo; faz calagem; faz adubação verde; e faz uso de material orgânico.

Esses resultados demonstram o quanto é grave o descaso quanto ao aspecto ambiental em ambos os grupos. A impressão é a de que os entrevistados estão completamente alheios à importância que tem o meio ambiente.

Os dados da Tabela 1 também mostram que os beneficiários do programa de reforma agrária do INCRA obtiveram Índice de Capital Social (ICS) de 0,691,indicam que, em média, os beneficiários desse programa possuem médio nível de capital social, ao passo que os não beneficiários obtiveram ICS de 0,347, o que classifica como baixo nível de capital social. Os indicadores que menos contribuíram para a construção desse índice nos dois grupos analisados foram: se todas as questões levantadas são respondidas; se as decisões são postas em prática; e se contribui com cotas ou taxas.

Tais resultados são consistentes, já que se espera que os beneficiários possuam índice de capital social superior aos não beneficiários. Isso porque, para se tornarem beneficiários, tiveram que demonstrar um nível de coordenação e associação considerável, sem o qual não teriam se tornado beneficiários da política de assentamento.

Em relação ao Índice Político Institucional (IPI), constata-se que os beneficiários do programa de assentamento agrícola do INCRA obtiveram IPI de 0,615 . Portanto, em média, os beneficiários desse programa podem ser classificados como tendo médio nível político institucional. O indicador que menos contribuiu para esse índice foi se recebeu produto ou serviço da Secretaria de Agricultura Municipal e/ou Estadual. Por outro lado, os não beneficiários ob- 


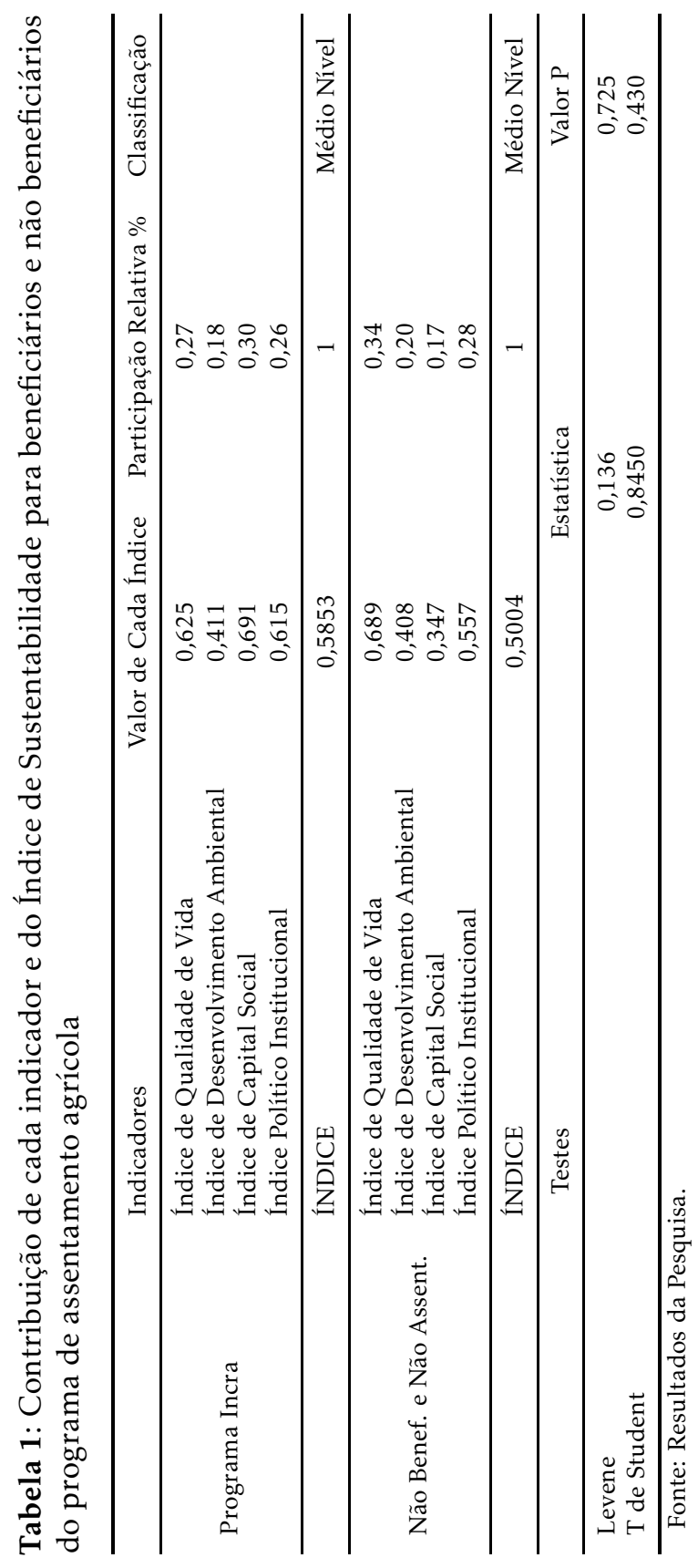


tiveram IPI de 0,557, classificando-se como médio nível político institucional, sendo que a participação em cursos de capacitação foi o indicador que menos contribuiu para a formação desse índice para esses agricultores entrevistados.

Pelo teste de Levene, pode-se afirmar que as variáveis possuem variância constante. Com base no teste $t$, verifica-se que os índices de ambos os grupos não são significativamente distintos, com 95\% de confiança.

\subsection{Resultados dos dados pareados}

Apresentação dos resultados do modelo Logit

Como se verifica pela Tabela 2, as variáveis referentes: a bens duráveis; se vota; se participou de cursos de capacitação, entre outras, não selecionam os grupos de forma significativa, uma vez que seus respectivos $P$ valores estão acima do limite de significância. Em outras palavras, elas não contribuem significativamente com o objetivo do modelo, que é o de separar ou destacar características que sejam decisivas para determinar a participação de um indivíduo no programa.

Em contrapartida, as variáveis referentes a: anos de estudo; ser convidado a participar das reuniões; e assistência técnica, selecionam os grupos de forma significativa com base no p-valor.

O Odds Ratio mede a variação do logaritmo natural da relação das probabilidades de ocorrência ou não de um evento. De outra maneira, ele compara indivíduos beneficiários e não beneficiários apenas com base na variável de interesse, considerando constantes as demais variáveis do modelo. Tomando como exemplo a variável 'se existe solidariedade entre os membros da comunidade', pode-se afirmar com base em seu Odds Ratio que o fato de não existir essa solidariedade entre os membros da comunidade reduz suas chances de participar do projeto em $87,02 \%$. Ao contrário, indivíduos que possuem assistência técnica aumentam de maneira acentuada suas chances de participar do programa.

Tabela 2: Resultado do modelo de regressão Logit entre beneficiários do programa de assentamento agrícola do INCRA e não beneficiários

\begin{tabular}{lrrrr}
\hline Variável & Odds Ratio & Std. Err. & \multicolumn{1}{c}{$Z$} & $P>l Z l$ \\
\hline Anos de Estudo & 0,8263 & 0,0639 & $-2,47$ & 0,014 \\
Idade & 0,9578 & 0,0267 & $-1,54$ & 0,123 \\
N de Indivíduos na Residência & 1,2627 & 0,2443 & 1,21 & 0,228 \\
Renda Não Agrícola & 0,9962 & 0,0019 & $-1,92$ & 0,055 \\
Bens Duráveis & 1,2626 & 0,4381 & 0,67 & 0,501 \\
É convidado a Participar das Reu- & 32,3179 & 54,8341 & 2,05 & 0,041 \\
niões & & & & \\
Existe Solidariedade entre os Mem- & 0,1298 & 0,1462 & $-1,81$ & 0,070 \\
bros da Comunidade & & & & \\
O Senhor Vota & 3,2672 & 4,7629 & 0,81 & 0,417 \\
Assistência Técnica & 22,7499 & 24,5625 & 2,89 & 0,004 \\
Participo de ursos de Capacitação & 1,5568 & 1,0822 & 0,64 & 0,524 \\
\hline Fonte: Resultados da Pesquisa. & & & &
\end{tabular}

O modelo Logit é avaliado considerando-se cinco critérios: valor da função de verossimilhança (log likelihood); valor do critério Akaike (AIC); valor do cri- 
tério Bayesiano (BIC); valor do pseudo R2 e percentual de casos corretamente classificados. Recomenda-se que o valor dos três primeiros critérios deva ser o menor possível, ao passo que os valores dos dois últimos critérios devam ser o maior possível.

Os resultados da Tabela 3 revelam que, como desejável, os três primeiros critérios possuem valores bem pequenos. Com base no Pseudo $R^{2}$, é possível afirmar que o modelo apresenta $56,55 \%$ de ajuste. Além disso, verifica-se que $88,24 \%$ dos casos foram corretamente classificados. Portanto, de posse desses critérios de qualidade do modelo, constata-se que se trata de um modelo bem ajustado.

Tabela 3: Resultados dos testes de qualidade do ajuste do modelo de regressão Logit entre beneficiários do programa de assentamento agrícola do INCRA e não beneficiários

\begin{tabular}{lc}
\hline Critério & Coeficiente \\
\hline Função de Verossimilhança (log likelihood) & $-35,1791$ \\
Valor do Critério AIC & 0,776 \\
Valor do Critério BIC & $-445,787$ \\
Valor do Pseudo R2 & 0,5655 \\
$\%$ De Casos Corretamente Classificados & $88,24 \%$ \\
\hline
\end{tabular}

Fonte: Resultados da Pesquisa.

Estimativas de impactos obtidas pelo Método Propensity Score Matching

Considerando os resultados dos ATTs (Average Effect of Treatment on Treated) da Tabela 4, pode-se afirmar que existe o indicativo de piora na qualidade de vida, no desenvolvimento ambiental, nas relações político-institucionais e na sustentabilidade do programa de assentamento agrícola do INCRA. Já com relação ao capital social, verifica-se que existe um indicativo de melhora ou vantagem para os beneficiários.

Esses resultados mostram que todos os índices, com exceção do índice de capital social, são favoráveis aos não beneficiários. Entretanto, esses valores dos ATTs são apenas estimativas. Para validá-los, faz-se necessário que se proceda ao teste bootstrapping, identificando assim os ATTs realmente significativos.

Com base nos dados da Tabela 5, verifica-se que efetivamente nenhuma das estimativas de ATT foi validada pelo teste. Entretanto, tomando-se apenas o indicativo apontado pelo sinal das estimativas de ATTs, o programa analisado só contribuiria positivamente com relação ao capital social.

Embora as análises dos dados pareados apontem para uma conclusão desfavorável ao programa de assentamento agrícola desenvolvido pelo INCRA, a viabilidade desse programa precisa ser analisada também por outros aspectos.

Nesse contexto, é relevante proceder a uma análise mais detalhada de cada índice analisado. Considerando o índice de qualidade de vida, verifica-se que dentre os quatorze indicadores que compõem esse índice, três deles que se referem a: forma de adquirir medicamentos; tratar a água de beber; e destino dado ao lixo, apresentam resultados graves dentro desses assentamentos. Com relação à forma de obtenção de medicamentos, 66\% dos entrevistados 


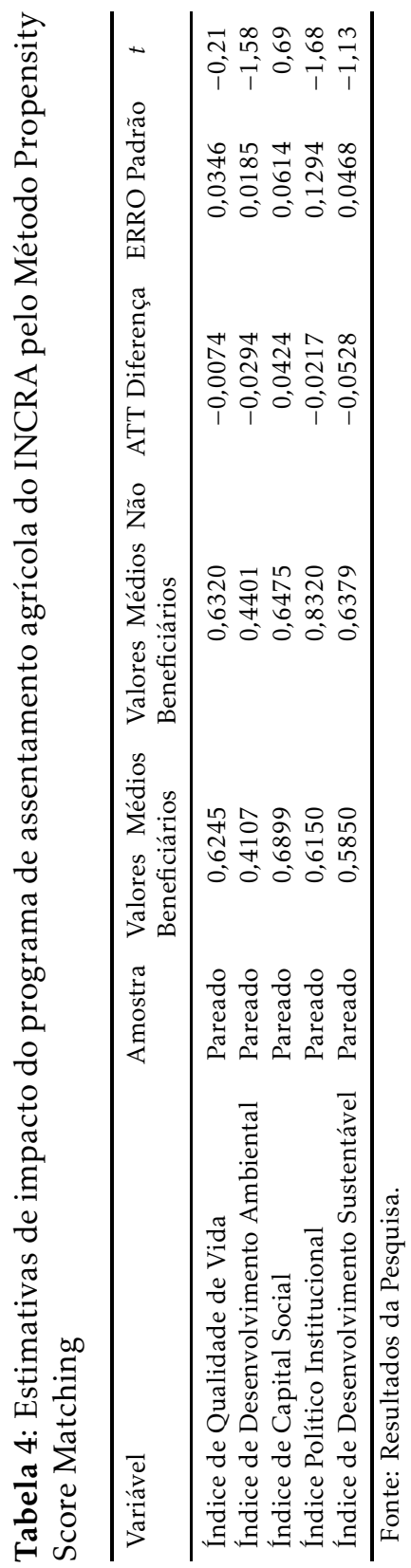


Tabela 5: Resultados do teste de hipótese para as estimativas de ATTs utilizando o Bootstrapping entre beneficiários do programa de assentamento agrícola do INCRA e não beneficiários

\begin{tabular}{lccrl}
\hline Variável & $\begin{array}{c}\text { Coeficiente } \\
\text { Observado }\end{array}$ & $\begin{array}{l}\text { Erro Padrão } \\
\text { Bootstrap }\end{array}$ & Z & P-Value \\
\hline Índice de Qualidade de Vida & $-0,0074$ & 0,0267 & $-0,28$ & 0,782 \\
Índice de Desenvolvimento Ambiental & $-0,0294$ & 0,0196 & $-1,50$ & 0,134 \\
Índice de Capital Social & 0,0424 & 0,0619 & 0,69 & 0,493 \\
Índice Político Institucional & $-0,0217$ & 0,1209 & $-1,79$ & 0,0730 \\
Índice de Desenvolvimento Sustentável & $-0,0528$ & 0,0402 & $-1,31$ & 0,1890 \\
\hline Fonte: Resultados da Pesquisa & & & &
\end{tabular}

afirmam só terem acesso a medicamentos fornecidos pelo Estado e com dificuldade. Dentre esses, 34\% afirmam não ter acesso de maneira alguma.

A maioria desses assentamentos não possui água dentro dos seus limites. Nos demais casos, o melhor cenário é a existência de pequenas cisternas, que acumulam o mínimo suficiente para o consumo humano durante o período não chuvoso. Isso ocorre em cerca de $60 \%$ dos casos, tornando quase impossível manter produções ou animais em períodos fora dos meses de chuva. Efetivamente, não existe o hábito de tratar a água de beber, sendo $74 \%$ dos casos. Quanto ao destino do lixo, 90\% afirmam descartar nas superfícies, ruas ou fazer queimadas.

No tocante ao índice de desenvolvimento ambiental, dos quatorze indicadores que o compõem, três deles que correspondem ao método de controle de pragas; quantos tipos de agrotóxicos são utilizados; e se realiza queimadas em suas atividades, apresentam resultados alarmantes. Com relação ao primeiro indicador, $74 \%$ dos entrevistados afirmam fazer uso de agrotóxicos como principal meio de combate às pragas. Quanto ao segundo, 74\% dos entrevistados beneficiários afirmam usar pelo menos um tipo de agrotóxico. Por fim, no que concerne ao terceiro indicador, $64 \%$ dos entrevistados afirmam fazer queimadas. Portanto, existe uma baixíssima consciência, por parte dos beneficiários, em preservar suas terras, que já são de baixa qualidade.

No que diz respeito ao índice de capital social, como já relatado, não há nada de relevante no resultado expresso, que não reflete mais que uma précondição para conseguirem o benefício.

Em relação ao índice político institucional, dos quatro indicadores que fazem parte desse índice, o indicador relativo ao recebimento de produtos ou serviços das Secretarias de Agricultura do Estado e do Município apresenta resultado alarmante, ou seja, $80 \%$ dos entrevistados afirmam não terem recebido quaisquer produtos ou serviços dessas secretarias. Existe pouca presença dessas esferas públicas na oferta de produtos ou serviços. Além disso, quando há a oferta, é de produtos e serviços de péssima qualidade em termos de eficiência e frequência, além de não cobrir a totalidade das famílias necessitadas.

\section{Considerações Finais}

Os resultados da análise sem pareamento das amostras evidenciaram que os beneficiários do assentamento agrícola do INCRA e os não beneficiários obtiveram médio nível de qualidade de vida, desenvolvimento ambiental e político institucional. Quanto ao Índice de Capital Social, verificou-se que o 
grupo dos beneficiários do programa de reforma agrária do INCRA obteve médio nível de capital social, ao passo que o grupo dos não beneficiários registrou baixo nível de capital social, não constituindo um resultado tão relevante, uma vez que possuir algum nível de capital social é uma pré-condição para serem beneficiários.

Os Índices de Sustentabilidade dos beneficiários do assentamento agrícola do INCRA e dos não beneficiários, sem pareamento das amostras, classificaramse como médio nível de sustentabilidade.

Portanto, pode-se concluir que, a partir da análise sem pareamento das amostras, os beneficiários do programa de assentamento só apresentam vantagem significativa, em relação aos não beneficiários, no aspecto capital social.

Considerando a análise a partir do pareamento das amostras e por meio do modelo Propensity Score Matching, o resultado do modelo apresenta, por meio dos ATTs, indicativo de impacto positivo do referido programa apenas sobre o Capital Social. Os demais aspectos tiveram indicativo negativo ou de piora. Porém, o teste bootstrapping não corrobora a melhora no Îndice de Capital Social.

Devido ao alto nível de concentração de terras verificado no Brasil, boa parte improdutivas e utilizadas para especulação, sugere-se a ampliação desses programas, porém, após mudanças múltiplas que os tornem mais eficientes quanto ao cumprimento de seus objetivos.

O programa precisa passar por profunda reforma em seu fundamento, sob risco de nunca alcançarem o objetivo de melhora de qualidade de vida dos assentados. Essas reformas devem passar pelo critério de escolha das propriedades, pelas pessoas a serem beneficiadas, pela localização, pelos valores limitados ao número de famílias, pela fiscalização das relações entre diretores das associações e representantes dos programas, por um estudo que vise a incluir, no bojo dos programas, outras políticas públicas; pela forma de assistência técnica, pelo estabelecimento de um critério de infraestrutura mínima e por diversos outros fatores.

Um importante fator que não foi abordado por este estudo, mas que se presenciou durante a pesquisa de campo, foi a questão da localização espacial desses assentamentos e suas possibilidades de escoamento da produção. É de domínio público o quanto a questão da localização tem figurado como um importante fator de competitividade e atração de investimentos. Especialmente nesse ponto, afirma-se, com contundência, frente ao vivenciado durante a pesquisa, que esses pequenos produtores familiares poderiam estar produzindo semicondutores, ao invés de bens primários de baixa elasticidade preço da demanda e, ainda assim, não seriam competitivos. Isso se deve às péssimas localizações e condições de acesso ainda piores da maioria desses assentamentos.

Outro fator de difícil mensuração que este estudo deixou de abordar, mas que possui uma dimensão humana tão forte e tão decisiva, capaz inclusive de relativizar completamente os resultados desse estudo, é a satisfação verificada por cada trabalhador rural beneficiado com seu pedacinho de terra.

\section{Referências Bibliográficas}

Abramovay, R. (2010), 'Desenvolvimento sustentável: Qual a estratégia para o brasil?'. 
URL: Disponivel: <http://www.abramovay.pro.br/artigos_cientificos/2010/ATT00341.pdf> Acesso em: 21 de maio de 2010

Alves, E. C. R. (2011), Condição do produtor em relação às terras do nordeste, Technical report, Informe Rural ETENE.

URL: Disponivel: <http://www.bnb.gov.br/content/aplicacao/etene/etene/docs/ire_ano5_n4.pdf> Acesso em 24 de abril de 2011

Alves, L. B. \& Bastos, R. P. (2011), 'Sustentabilidade em silvânia (go): o caso dos assentamentos rurais são sebastião da garganta e joão de deus', Revista de Economia e Sociologia Rural 49(2), 419-448.

Barreto, R. C. S. (2004), Políticas públicas e desenvolvimento rural sustentável no estado do ceará: estudo de caso, Dissertação de mestrado em economia rural, Universidade Federal do Ceará.

Barreto, R. C. S., Khan, A. S. \& Lima, P. V. P. S. (2005), 'Sustentabilidade dos assentamentos no município de caucaia-ce', Revista de Economia e Sociologia Rural 43(2), 225-247.

Buainain, A. M. c. e. a. (2008), Luta pela terra, reforma agrária e gestão de conflitos no Brasil, Editora da Unicamp.

CMMAD, C. M. s. M. A. e. D. (1991), Nosso Futuro Comum., Fundação Getúlio Vargas.

Damasceno, N. P., Khan, A. S. \& Lima, P. V. P. S. (2011), 'O impacto do pronaf sobre a sustentabilidade da agricultura familiar, geração de emprego e renda no estado do ceará', Revista de Economia e Sociologia Rural 49(1), 129-156.

Duarte, G. B., Sampaio, B. \& Sampaio, Y. (2009), 'Programa bolsa família: impacto das transferências sobre os gastos com alimentos em famílias rurais', Revista de Economia e Sociologia Rural 47(4), 903-918.

Guerra, R. M. N. (2002), É possível atingir a sustentabilidade nos assentamentos de reforma agrária na amazônia legal? o caso do pds são salvador no estado do acre, Dissertação de mestrado em desenvolvimento sustentável, Universidade de Brasília, Universidade de Brasília, Brasília-DF.

Hartmann, P. (2000), Reforma agrária no ceará - uma análise dentro de perspectivas econômicas, in J. o. Amaral Filho, ed., 'Federalismo fiscal e transformações recentes no Ceará', Edições INESP.

Heredita, B., Medeiros, L., Palmeira, M., Cintrão, R. \& Leite, S. P. (2002), 'Análise dos impactos regionais da reforma agrária no brasil', Estudos Sociedade e Agricultura pp. 73-111.

URL: Disponivel em: <http://bibliotecavirtual.clacso.org.ar/ar/libros/brasil/cpdalestudos/dezoito/heredi18.htm> Acesso em: 21 de abril de 2011

INCRA (2009), 'Projetos e programas 2009'.

URL: Disponivel em: <http://www.incra.gov.br/portal/index.php?option $=$ com_contentEview $=$ section $\delta$ layout $=$ blogEid $=6$ EItemid $=59>\quad$ Acesso em 12 de fevereiro de 2011 
IPECE, I. d. P. e. E. E. d. C. (2011), Divisão político-administrativa e regional, Anuário estatístico do ceará, Instituto de Pesquisa e Estratégia Econômica do Ceará.

URL: Disponivel em: <http://www2.ipece.ce.gov.br/publicacoes/anuario/anuario2011/fisiografia/divisao.htm> Acesso em: 19 de dezembro de 2012

Leite, S. (2011), 'Impactos regionais da reforma agrária no brasil: aspectos políticos, econômicos e sociais'.

URL: Disponivel em: <http://www.mda.gov.br/portal/nead/arquivos/view/textosdigitais/Artigo/arquivo_27.pdf> Acesso em: 17 de abril de 2011

Leite, S. P. \& Ávila, R. V. (2007), 'Reforma agrária e desenvolvimento na américa latina: rompendo com o reducionismo das abordagens economicistas', Revista de Economia e Sociologia Rural 45(3), 777-805.

Levene, H. (1960), Robust test for equality of variances, in I. e. a. Olkin, ed., 'Contributions to probability and statistics: essays in Honor of Harold Hotteling', Stanford University Press.

Magalhães, A. M., Silveira Neto, R., Dias, F. M. \& Barros, A. R. (2006), 'A experiência recente do pronaf em pernambuco: uma análise por meio de propensity score', Economia Aplicada 10(1), 57-74.

Pedro, J. (2008), A reforma agrária, in 'Brava Gente - Cap. 14.', UNESP.

URL: Disponivel em: <http://www4.fct.unesp.br/docentes/geo/bernardo/BRAVA\%20GENTE/cap.14_A_reforma_agraria.pdf> Acesso em: 14 de março de 2011

Resende, A. C. C. \& Oliveira, A. M. H. C. (2008), 'Avaliando resultados de um programa de transferência de renda: o impacto do bolsa-escola sobre gastos das famílias brasileiras', Estudos Econômicos 38(2), 235-265.

Sachs, I. (2002), Caminhos para o desenvolvimento sustentável, Garamond.

Sachs, I. (2008), Desenvolvimento: includente, sustentável, sustentado., Garamond.

Sousa, M. C., Khan, A. S., Passos, A. T. B. \& Lima, P. V. P. S. (2005), 'Sustentabilidade da agricultura familiar em assentamentos de reforma agrária no rio grande do norte', Revista Econômica do Nordeste 36(1), 96-120.

Triola, M. F. (1999), Introdução à Estatística, LTC. 